\title{
Experimental investigation of added mass effects on a hydrofoil under cavitation conditions
}

\author{
O. De La Torre ${ }^{\mathrm{a}, *}$, X. Escaler ${ }^{\mathrm{a}}$, E. Egusquiza ${ }^{\mathrm{a}}$, M. Farhat ${ }^{\mathrm{b}}$ \\ ${ }^{a}$ Center for Industrial Diagnostics, Universitat Politècnica de Catalunya, Av. Diagonal 647, 08028 Barcelona, Spain \\ ${ }^{\mathrm{b}}$ Laboratory for Hydraulic Machines, École Polytechnique Fédérale de Lausanne (EPFL), Lausanne, Switzerland
}

\section{A R T I C L E I N F O}

\section{Article history:}

Received 27 December 2011

Accepted 7 January 2013

Available online 13 March 2013

\section{Keywords:}

Added mass

Sheet cavitation

Supercavitation

PZT patch

Entrained mass

\begin{abstract}
A B S T R A C T
The influence of leading edge sheet cavitation and supercavitation on the added mass effects experienced by a 2-D NACA0009 truncated hydrofoil has been experimentally investigated in a hydrodynamic tunnel. A non-intrusive excitation and measuring system based on piezoelectric patches mounted on the hydrofoil surface was used to determine the natural frequencies of the fluid-structure system. The appropriate hydrodynamic conditions were selected to generate a range of stable partial cavities of various sizes and also to minimize the effects of other sources of flow noise and vibrations. The main tests were performed for different sigma values under a constant flow velocity of $14 \mathrm{~m} / \mathrm{s}$ and for incident angles of both $1^{\circ}$ and $2^{\circ}$. Additionally, a series of experiments in which the hydrofoil was submerged in air, partially and completely submerged in still water and without cavitation at 7 and $14 \mathrm{~m} / \mathrm{s}$ were also performed. The maximum added mass effect occurs with still water. When cavitation appears, the added mass decreases because the cavity length is increased, and the added mass is minimum for supercavitation. A linear correlation is found between the added mass coefficients and the entrained mass that accounts for the mean density of the cavity, its dimensions and its location relative to the specific mode shape deformation.
\end{abstract}

(c) 2013 Elsevier Ltd. All rights reserved.

\section{Introduction}

The prediction of the dynamic behavior of a structure during its design phase is a key issue. The calculation of modal parameters such as natural frequencies and mode shapes is necessary to anticipate its response to an external dynamic load. An extensive body of academic literature addresses the topics of theoretical, experimental and computational approximations to the dynamic response of solid bodies with multiple configurations. Blevins (1979) summarized many of the most important formulas and principles used in this field.

If a solid structure is partially or completely submerged in a high-density fluid, its dynamic response will differ from its response in vacuum (Blevins, 1979; Brennen, 1982). This phenomenon is due to the added mass effect, which is a result of the inertia of the surrounding fluid entrained by the accelerating structure. This phenomenon has been widely investigated for various solid configurations in air and in both fully and partially submerged in water.

\footnotetext{
Abbreviations: FFT, Fast Fourier transform; FSI, fluid structure interaction; JTFA, Joint Time Frequency Analysis; PZT, lead zirconate titanate; STFT, Short Time Fourier transform

* Corresponding author. Tel.: +349340159 45; fax: +34934015812.

E-mail addresses: oscar.de.la.torre@mf.upc.edu, dela.oscar@gmail.com (O. De La Torre).
} 


\begin{tabular}{|c|c|c|c|}
\hline \multicolumn{2}{|c|}{ Nomenclature } & $\mathrm{V}$ & flow velocity [m/s] \\
\hline A & constant $[\mathrm{N}]$ & $X_{o}$ & amplitude of vibration in a given \\
\hline$A_{\text {fluid }}$ & added mass $[\mathrm{kg}]$ & & direction $[\mathrm{m}]$ \\
\hline B & constant $[\mathrm{N}]$ & $y$ & volume $\left[\mathrm{m}^{3}\right]$ \\
\hline $\begin{array}{l}B_{\text {fluid }} \\
C\end{array}$ & $\begin{array}{l}\text { added damping }[\mathrm{kg} / \mathrm{s}] \\
\text { profile chord length }[\mathrm{m}]\end{array}$ & $\mathrm{Y}$ & displacement in vertical direction [m] \\
\hline $\begin{array}{l}C \\
C_{M}\end{array}$ & $\begin{array}{l}\text { structural damping matrix }[\mathrm{kg} / \mathrm{s}] \\
\text { added mass coefficient }=\left(f_{\text {vacuum }_{i}} / f_{\text {fluid }_{i}}\right)^{2}-1\end{array}$ & \multicolumn{2}{|c|}{ Greek symbols } \\
\hline CSR & $\begin{array}{l}\text { cavitation surface ratio }=\text { cavity surface/pro- } \\
\text { file surface }\end{array}$ & $\begin{array}{l}\rho \\
\omega\end{array}$ & $\begin{array}{l}\text { fluid density }\left[\mathrm{kg} / \mathrm{m}^{3}\right] \\
\text { fundamental frequency }[\mathrm{rad} / \mathrm{s}]\end{array}$ \\
\hline $\bar{d}$ & mean displacement [m] & $\vartheta$ & kinematic viscosity $\left[\mathrm{m}^{2} / \mathrm{s}\right]$ \\
\hline$D$ & diameter [m] & $\sigma$ & sigma value $=P_{\infty}-P_{v} /\left(1 / 2 \rho V^{2}\right)$ \\
\hline EM & $\begin{array}{l}\text { entrained mass } \\
\mathrm{EM}_{i}=m_{i} / \Delta Y_{\max i}=\sum_{j} \bar{\rho}_{j}\left(\dot{d}_{j} \mathrm{AREA}_{j}\right)\end{array}$ & $\begin{array}{l}\alpha \\
\bar{\rho}\end{array}$ & $\begin{array}{l}\text { void fraction }=y_{v} /\left(y_{v}+y_{l}\right) \\
\text { mean density }\left[\mathrm{kg} / \mathrm{m}^{3}\right]=\rho_{v} \alpha+\rho_{l}(1-\alpha)\end{array}$ \\
\hline$f$ & fundamental frequency $[\mathrm{Hz}]$ & & \\
\hline $\begin{array}{l}f_{1} \\
f_{2}\end{array}$ & $\begin{array}{l}\text { first natural frequency } \\
\text { second natural frequency }\end{array}$ & \multicolumn{2}{|c|}{ Subscripts } \\
\hline $\begin{array}{l}f_{3} \\
F\end{array}$ & $\begin{array}{l}\text { third natural frequency } \\
\text { force applied by the entrained fluid [N] }\end{array}$ & air & quantity measured in air \\
\hline$k_{i}$ & $\begin{array}{l}\text { modal stiffness }[\mathrm{N} / \mathrm{m}] \\
\text { matura }\end{array}$ & fluid & quantity measured in a generic fluid \\
\hline$K$ & stiffness matrix $[\mathrm{N} / \mathrm{m}]$ & half wett & ted quantity measured in a structure partially \\
\hline$l$ & cavity length $[\mathrm{m}]$ & & mode shape \\
\hline$L$ & total number of samples & & node number \\
\hline M & mass matrix $[\mathrm{kg}]$ & $k$ & sample number \\
\hline$m_{i}$ & modal mass [kg] & & quantity measured in liquid phase \\
\hline $\begin{array}{l}N \\
P\end{array}$ & number of nodes & $\max$ & maximum value \\
\hline $\begin{array}{l}P_{\infty} \\
P\end{array}$ & upstream pressure [Pa] & & quantity measured in vapor phase \\
\hline $\begin{array}{l}P_{v} \\
R^{2}\end{array}$ & coefficient of determination [dimensionless] & vacuum & quantity measured in vacuum \\
\hline $\mathrm{t}$ & time [s] & & quantity measurea in water \\
\hline
\end{tabular}

A study was performed by Lindholm et al. (1965) on cantilever beams both in air and submerged in water. Experimental results with natural frequencies showed reasonably good agreement with plate theory approximations. Consequently, empirical correction factors were obtained for the added mass taking into account the aspect and thickness ratios of the beams. Sewall et al. (1983) successfully compared experimental and analytical data related to the vibration frequency of the fundamental mode of a three-sided membrane in air. They also found that the added mass effect on a cylinder was overestimated when using the same analytical method. More recently, Kimber et al. (2009) studied the interaction between two cantilever structures vibrating in air for various configurations. They verified that resonance frequencies and aerodynamic damping depend on the vibrating phase difference between the plates.

Furthermore, several analytical models have been built to carefully analyze the dependency of the added mass effect on various parameters. For example, Blevins (1979) determined that the added mass of a structure vibrating in a still fluid is essentially a function of the geometry of its surface, its relative position to the boundary conditions, the amplitude and direction of its vibration and a Reynolds-like coefficient as shown in the following formula:

$$
A_{\text {still fluid }}=\rho f\left(\text { geometry, } \frac{X_{o}}{D}, \frac{f D^{2}}{\vartheta}\right),
$$

where $X_{o}$ is the amplitude of vibration in a given direction, $D$ is the characteristic length, $f$ is the frequency of vibration and $\vartheta$ is the kinematic viscosity of the fluid. Amabili (1996) presented a model to estimate the natural frequencies and mode shapes of partially filled shells. Conca et al. (1997) showed that the added mass matrix for a mechanical structure vibrating in an incompressible fluid does not depend on the viscosity. Yadykin et al. (2003) found that for a flexible plate oscillating in a fluid, either an increase of the order of the mode of vibration or a decrease of the aspect ratio leads to a decrease of the added mass effect.

In the field of hydraulic machinery, fluid-structure interaction (FSI) phenomena involving hydrofoils are a major concern, and several investigations have been performed on this topic. Ducoin et al. (2010a) experimentally studied the vibrations induced in a hydrofoil by the laminar to turbulent boundary layer transition and determined their significance and dependence on the vortex shedding frequency. Olofsson (1996) experimentally studied the dynamic performance of partially submerged propellers. Using numerical simulations, Moussou (2005) developed methods and solutions for two 
coaxial cylinders with quiescent fluid between them. Additionally, Münch et al. (2010) developed numerical simulations for an oscillating hydrofoil under incompressible turbulent flow. FSI phenomena under cavitating flows, however, have not been extensively studied. Previous studies have focused on analyzing the profile response. For example, Amromin and Kovinskaya (2000) analyzed the vibration of an elastic wing with an attached cavity in a perturbed flow. They found that two different frequency bands were excited: a low band associated with cavity oscillations and a high band associated with wing resonances. Numerical investigations have also been performed. For example, Young (2007) performed a coupled 3-D simulation to analyze the time-dependent hydroelastic response of cavitating propellers, and Young and Savander (2011) compared the mechanical efficiency of various surface-piercing propeller designs. Finally, Ducoin et al. (2010b) presented a method to simulate FSI problems under cavitating flows. Recently, Benaouicha and Astolfi (2012) made a very interesting theoretical study of the added mass under cavitating flow for different body geometries.

Although some numerical examinations of added mass effects under supercavitating flows have been reported, such as that of Fine et al. (2001), no experimental results quantifying the added mass effects of partial sheet cavitation on a hydrofoil have been presented. Other effects caused by cavitation, however, have been extensively reviewed, such as the modification of lift and drag (Amromin et al., 2003) and the risk of cavitation erosion (Escaler et al., 2007).

The presence of cavitation and the associated added mass effects are relevant to applications in water turbines and pumps. Currently, only the effects of water surrounding turbine runners have been investigated both experimentally and numerically, but these investigations have not considered the presence of cavitation on the blades (see, for example, the work of Rodriguez et al. (2006) and Liang et al. (2007)). It should be noted that the current trend of regular operation of the hydraulic machines beyond their design specifications renders the machines more prone to cavitation problems. It is, therefore, necessary to estimate dynamic responses under such extreme conditions to reduce damage due to material fatigue.

\section{Background}

The general equation of motion for a body vibrating in a still fluid is

$$
M \ddot{X}+C \dot{X}+K X=F,
$$

where $M$ is the mass of the body, $C$ is the structural damping, $K$ is the stiffness and $F$ is the force applied to the body by the entrained fluid. Assuming that the fluid force takes the form

$$
F=a \sin \omega t+b \cos \omega t,
$$

the general equation of motion for a body vibrating in a fluid may be written as

$$
\left(M+A_{\text {fluid }}\right) \ddot{X}+\left(C+B_{\text {fluid }}\right) \dot{X}+K X=0,
$$

where $A_{\text {fluid }}$ and $B_{\text {fluid }}$ are the added mass and the added damping respectively. As shown in (4), the added mass is in phase with the acceleration of the structure and the added damping is in phase with the velocity.

Typically, the fundamental frequency of mode $i$ for a lightly damped structure vibrating in-vacuum conditions can be expressed as

$$
\omega_{i}=\sqrt{\frac{k_{i}}{m_{i}}},
$$

where $k_{i}$ and $m_{i}$ are the modal stiffness and the modal mass respectively. When submerged in a fluid, the dynamic response of a solid body is altered by the effect of the fluid added mass. Consequently, the ratio between the natural frequency in water, $f_{\text {fluid }_{i}}$, and the natural frequency in air, $f_{\text {vacuum }_{i}}$, is approximately

$$
\frac{f_{\text {fluid }_{i}}}{f_{\text {vacuum }_{i}}} \cong \sqrt{\frac{1}{\left(1+\frac{A_{\text {fluid }_{i}}}{m_{i}}\right)}}
$$

Using (6), the added mass coefficient, $C_{M}$, can be finally defined as

$$
C_{M}=\frac{A_{\text {fluid }_{i}}}{m_{i}}=\left(\frac{f_{\text {vacuum }_{i}}}{f_{\text {fluid }_{i}}}\right)^{2}-1 .
$$

Cavitation is defined by Knapp et al. (1970) as the phenomenon that occurs when a liquid reaches a state in which vapor cavities are formed and grow due to dynamic reductions to the vapor pressure of the liquid at constant temperature. These cavities can adopt several configurations on hydrofoils submerged in a flow including traveling bubbles, attached cavities and vortices, each of which was described by Franc and Michel (2004). For the present study, we focused on stable macro-cavities that develop on the leading edge and attach to the suction side of the hydrofoil surface. Sheet cavitation occurs when a region of separated flow is filled with vapor/gas and extends downstream until its closure zone. The length of the sheet cavity, $l$, with respect to the chord length, $c$, increases with decreasing sigma coefficient, $\sigma$. Fig. 1 shows the morphology of the sheet cavitation considered in our tests. The behavior of cavity lengths extending further than one-half 


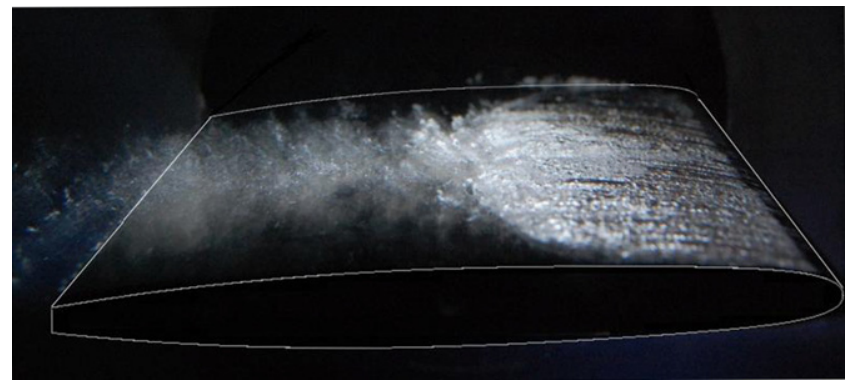

Fig. 1. Sheet cavitation on the suction side of the truncated NACA 0009 hydrofoil (flow from right to left).

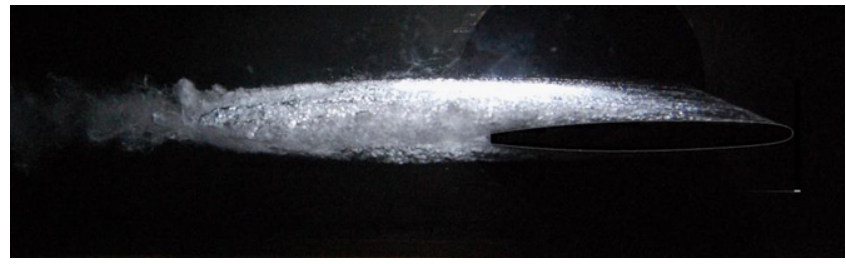

Fig. 2. Supercavitation on the truncated NACA0009 hydrofoil (flow from right to left).

of the chord tends to be unstable and exhibits significant fluctuations. These fluctuating conditions were avoided during our experiments.

The photograph in Fig. 1 also shows the complex morphology of the two-phase flow that forms the cavitation sheet, as has been experimentally verified by Stutz and Reboud (1997). In fact, the sheet is not a pure vapor pocket, but a nonhomogeneous mixture of vapor/water structures of unknown density. This characteristic is relevant when quantifying added mass effects. For instance, Ishii (1975) proposed a definition of the cavity mean density, $\bar{\rho}$, that depends on the gas/vapor content of the cavity, specifically its void fraction $\alpha$, which is defined as

$$
\begin{aligned}
& \bar{\rho}=\rho_{v} \alpha+\rho_{l}(1-\alpha), \\
& \alpha=\frac{y_{v}}{y_{v}+y_{l}},
\end{aligned}
$$

where $y_{v}$ and $y_{l}$ are the volumes of the cavity in gas and liquid phases respectively.

The void fraction, $\alpha$, is a local variable that determines the sonic velocity within the cavity and is related to the modal properties of the medium. Some investigations report experimental values of $\alpha$ for attached cavities (Coutier-Delgosha et al., 2006; Stutz and Legoupil, 2003; Stutz and Reboud, 1997). Nevertheless, the types and morphologies of cavitation in these studies differ from the cavitation conditions produced during our tests. Recently, Aeschlimann et al. (2011) used an $\mathrm{X}$-ray attenuation measurement to determine the void ratio in a cavitating mixing layer with acceptable accuracy.

\section{Objective and methodology}

The primary objective of our experiment was to quantify the added mass effects on the dynamic response of a truncated NACA0009 hydrofoil under various cavitation conditions through the coefficient $C_{M}$ (7). In particular, various sheet cavities with different lengths (Fig. 1) and supercavitation (Fig. 2) were investigated. These conditions were generated by reducing sigma at constant flow velocity in a high-speed cavitation tunnel for two incident angles.

An excitation and measuring system capable of operating without any significant effects on either the flow field or the sheet cavity was developed and used.

A series of complementary tests considered the hydrofoil in atmospheric air, partially and completely submerged in still water and with flowing water without cavitation at two different velocities.

Additionally, the cavitation tunnel operating parameters were recorded, and the cavitation conditions were photographed to estimate the cavity dimensions and morphology.

Finally, the $C_{M}$ results were correlated with $\sigma / 2 \alpha$ and with a new parameter corresponding to the entrained mass of the two-phase flow as defined by (12). Accordingly, it was possible to validate the results and to identify those factors that significantly influenced them. 


\section{Experimental set up and methods}

\subsection{Excitation and measurement system on hydrofoil}

An aluminum NACA0009 hydrofoil with a $100 \mathrm{~mm}$ chord, $150 \mathrm{~mm}$ span and a truncated trailing edge was used in the test section of the EPFL High-Speed Cavitation Tunnel as described by Avellan et al. (1987). This test facility is composed of a closed loop with a rectangular test section of $150 \times 150 \times 750 \mathrm{~mm}$ as inner dimensions. A honeycomb, a screen and a contraction nozzle are installed upstream of the test section to avoid macroscopic flow rotation and to reduce the turbulence intensity. The blockage ratio based on the hydrofoil maximum thickness of $9.9 \mathrm{~mm}$ is $6.6 \%$, and the maximum free stream velocity at test section inlet, $V$, is $50 \mathrm{~m} / \mathrm{s}$. The operating flow parameters that are controlled are $V$ and the cavitation number, $\sigma=P_{\infty}-P_{v} /\left(1 / 2 \rho V^{2}\right)$, with $P_{\infty}, P_{v}$ and $\rho$ representing the reference pressure at the test section inlet, the vapor pressure and the fluid density, respectively.

The truncated trailing edge thickness is $3.22 \mathrm{~mm}$. To trigger a more uniform and homogeneous cavitation sheet along the profile span, a spanwise strip of roughness was artificially created. The strip consists of a 2 mm band of sand glued on the suction side next to the stagnation point with a thickness of approximately $200 \mu \mathrm{m}$ (see detail on the right side of Fig. 4).

Two PZT patches made of piezoelectric ceramic material based on modified lead zirconate titanate were used as excitation and measuring systems. Each patch had a length of $61 \mathrm{~mm}$, a width of $35 \mathrm{~mm}$ and a thickness of $0.5 \mathrm{~mm}$ (Fig. 3 ). To keep the hydrofoil geometry and to avoid affecting the flow around the profile, the NACA0009 hydrofoil suction side was mechanized to embed the two patches (see the left side of Fig. 4). They were electrically isolated with a layer of epoxy, and the connections were protected and hidden inside the structure.

This type of patch and mounting was shown to work well in a preliminary test with stainless steel plates of similar dimensions and aspect ratios to the typical tunnel hydrofoils, both in air and submerged in still water. First, the intensity of the excitation signal required to sufficiently excite the plates was determined. Second, different types of excitation signals were applied, and the responses were measured in various points of the plates with accelerometers. Consequently, the experimentally determined plate natural frequencies and mode shapes were successfully compared with the theoretical ones found in the literature and also with those obtained with a classic impact test. Conversely, the use of the patch as a sensor was also verified by comparing its signals with those from the accelerometers.

The piezoelectric effect was discovered with quartz crystals in 1880 by Pierre and Marie Curie and refers to the electric potential that certain materials spontaneously generate when a pressure is applied to them. The inverse piezoelectric effect also occurs, in which a material changes its shape when exposed to an electric potential. Taking advantage of this duality, these patches may be used as either sensors or actuators. In excitation mode, a voltage is applied to the metallized surfaces that surround the ceramic material. The resulting electric field causes a contraction of the material perpendicular to the direction of the electric field. If glued to a solid substrate, the contraction of the patch exerts a force on the substrate

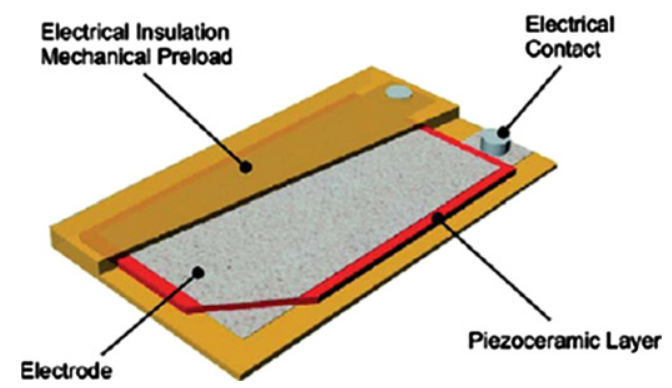

Fig. 3. PZT patch conforming parts from PI Ceramic GmbH.
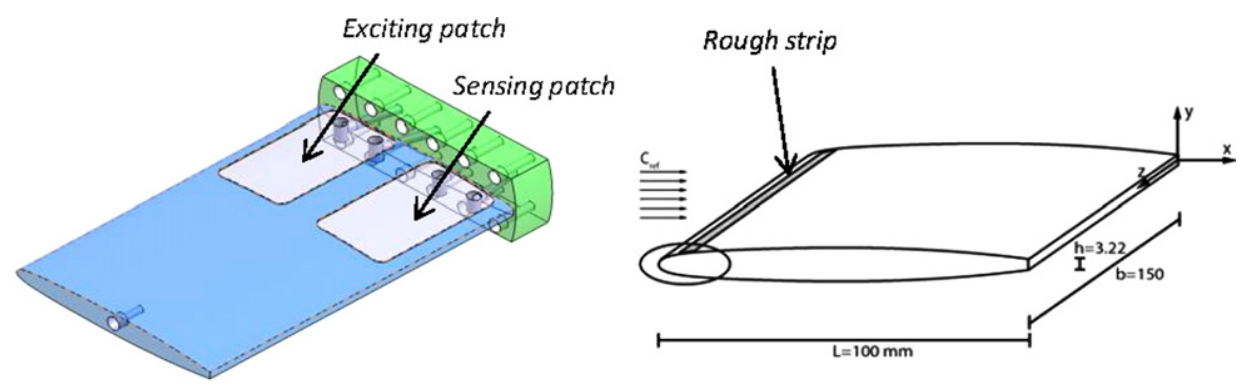

Fig. 4. Truncated NACA0009 design (left) and detail of the leading edge roughness (right). 
through its surface. In sensing mode, the patches generate an electric voltage output as a response to a change in their shape. In our case, the patch next to the leading edge was used to excite the hydrofoil and the patch next to the trailing edge was used to measure the hydrofoil response (left of Fig. 4).

A fast sine sweep (chirp) signal was used to excite a given frequency band. The sine wave frequency was linearly increased at a rate of $2 \mathrm{~Hz} / \mathrm{s}$ during a period of $120 \mathrm{~s}$. The output of the signal generator was amplified to feed the patch located next to the leading edge. Because the magnitude of the contracting force is dependent on the strength of the electric field, a relatively high input voltage is usually required to produce enough deformation. The voltage range for the patches used in the present study was from negative $100 \mathrm{~V}$ to positive $400 \mathrm{~V}$. Consequently, a voltage amplifier with an amplification factor of 25 was used to feed the exciting patch.

The acquisition and conditioning system consisted of a 16 byte A/D converter and recorder with eight simultaneous input channels and a selectable sampling frequency with a maximum of $250 \mathrm{kS} / \mathrm{s}$. For our tests, the excitation signal produced by the signal generator, the amplified signal feeding the patch and the measured response were recorded simultaneously.

\subsection{Hydrodynamic conditions}

To identify suitable flow conditions for the experiments, a wide range of flow speeds, sigma values and incidence angles were tested to map the hydrofoil cavitation behavior. The purpose of these trials was to find well-defined and stable testing conditions. We intended to generate a stable sheet cavity on the hydrofoil suction side with small length fluctuations. This partial cavity had to be as two-dimensional as possible with constant length in the spanwise direction. Moreover, the flow conditions had to avoid or minimize hydrodynamic sources of noise and vibration such as vortex shedding. Finally, the conditions had to prevent any cavitation from appearing on the pressure side.

It was observed that for flow velocities between 15 and $20 \mathrm{~m} / \mathrm{s}$, the cavities were not stable, and large vibrations were induced in the hydrofoil. In the range from 5 to $10 \mathrm{~m} / \mathrm{s}$, the stable cavities were not uniform along the whole span, and the two-phase mixture was not sufficiently homogeneous. For flow velocities of approximately $11 \mathrm{~m} / \mathrm{s}$, a lock-in phenomenon occurs. For incident angles between $3^{\circ}$ and $5^{\circ}$, the cavity was not attached to the hydrofoil suction side, and unstable shear cavitation took place instead. For incident angles lower than $1^{\circ}$, the vortex shedding was significant, and cavitation on the pressure side also appeared. Consequently, the cavitation tunnel upstream velocity was fixed at $14 \mathrm{~m} / \mathrm{s}$, and two incidence angles of $1^{\circ}$ and $2^{\circ}$ were selected.

Under these conditions, steady partial cavities were obtained, with lengths ranging from $2 \%$ to $44 \%$ of the chord for an incident angle of $1^{\circ}$ and from $2 \%$ to $75 \%$ for an incident angle of $2^{\circ}$ by decreasing sigma. Photographs from the top and lateral sides of the test section were taken during the tests. They were obtained with a $50 \mu$ s duration flash lamp synchronized with a digital photo camera. The supercavitation condition was also investigated for both incident angles. This condition occurs when the cavity length extends beyond the hydrofoil trailing edge as shown in Fig. 2.

\subsection{Identification of natural frequencies}

The modal behavior of the NACA0009 hydrofoil mounted in the cavitation tunnel test section was previously characterized by Ausoni et al. (2007). Its modes of vibration can be compared to those of a cantilever beam. The first mode $\left(f_{1}\right)$ is a bending mode, the second mode $\left(f_{2}\right)$ corresponds to the torsion, and the third mode $\left(f_{3}\right)$ corresponds to the second bending. Fig. 5 shows a schematic view of these mode shapes that were obtained from a numerical simulation.

These first three natural frequencies were determined with the hydrofoil mounted inside the test section, both when the test section was empty and full of still water. Another test was performed with the test section partially full of water with the free surface at the same level than the hydrofoil symmetry axis. In this case, the hydrofoil was in full contact with the water on its lower side and was in contact with air at atmospheric pressure on its upper side.

Tables 1 and 2 indicate the starting and ending frequencies of the chirp signals used to identify the resonances for no-cavitation conditions and for cavitation conditions, respectively. It should be mentioned that the first bending mode was not considered for discussion during cavitation conditions because a contact of the blade tip cross section surface with
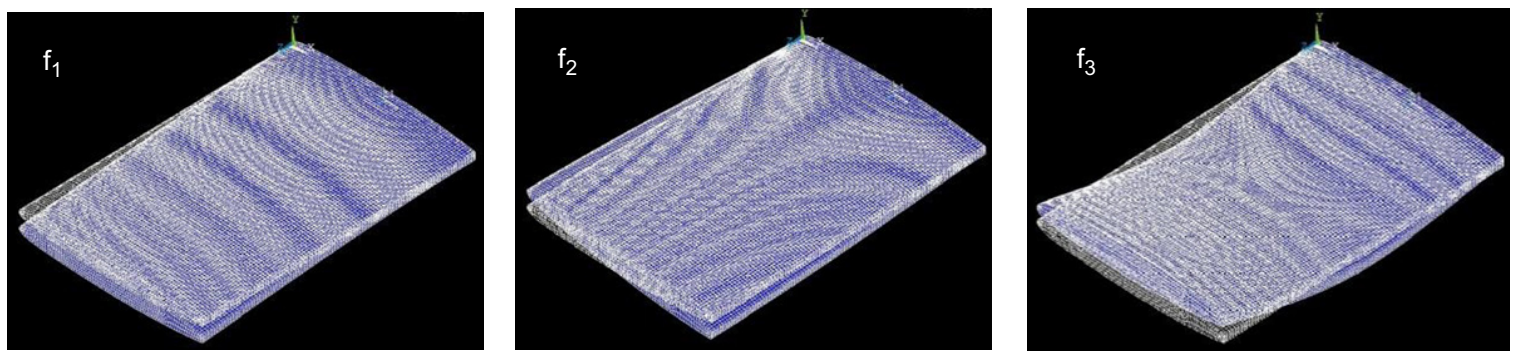

Fig. 5. Simulated mode shapes for the first bending $f_{1}$ (left), torsion $f_{2}$ (middle) and second bending $f_{3}$ (right) modes. 
Table 1

Chirp starting and ending frequencies for tests with air and water without cavitation.

\begin{tabular}{lll}
\hline $\mathrm{Hz}$ & Air & Water \\
\hline$f_{1}$ & $140-380$ & $0-240$ \\
$f_{2}$ & $880-1120$ & $490-730$ \\
$f_{3}$ & $1500-1740$ & $760-1000$ \\
\hline
\end{tabular}

Table 2

Chirp starting and ending frequencies for tests with cavitation.

\begin{tabular}{|c|c|c|c|c|c|c|}
\hline \multirow[t]{2}{*}{$\mathrm{Hz}$} & \multicolumn{6}{|l|}{$l / c$} \\
\hline & 0.02 & 0.054 & 0.114 & 0.318 & 0.442 & $>1$ \\
\hline$f_{2}$ & $490-730$ & $570-810$ & $570-810$ & $570-810$ & $570-810$ & $880-1120$ \\
\hline$f_{3}$ & $760-1000$ & $\begin{array}{l}810-1050 \\
1050-1290\end{array}$ & $\begin{array}{l}810-1050 \\
1050-1290\end{array}$ & $\begin{array}{l}810-1050 \\
1050-1290 \\
1290-1530\end{array}$ & $\begin{array}{l}810-1050 \\
1050-1290 \\
1290-1530\end{array}$ & $1500-1740$ \\
\hline
\end{tabular}

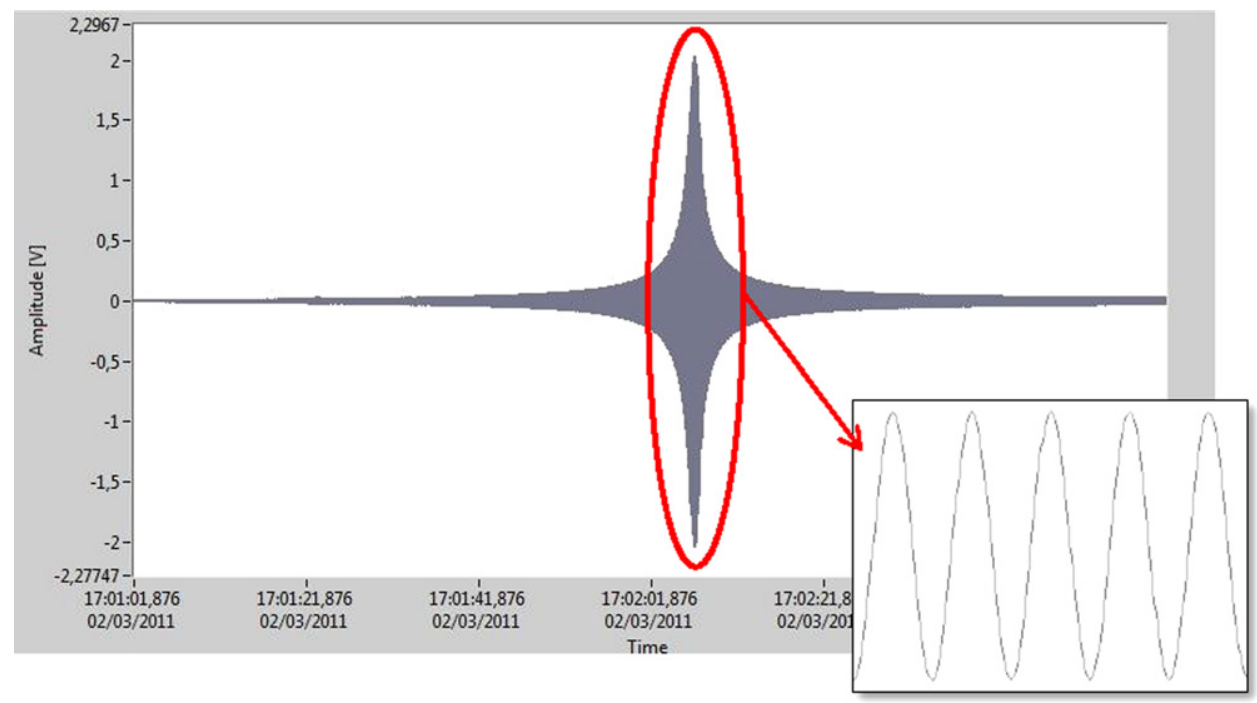

Fig. 6. Amplified hydrofoil response during a chirp excitation passing by $f_{1}$.

the lateral test section wall was detected during resonance. The results under cavitation conditions, therefore, only correspond to $f_{2}$ and $f_{3}$.

The identification of the natural frequencies of the hydrofoil from the measured responses was performed using several signal processing methods capable of addressing the inherently transient nature of the excitation signal and the flow noise. This method consisted of finding the excitation frequency that provoked the maximum amplitude of the hydrofoil response resulting from resonance with a natural frequency.

Under conditions with no flow, the time signal alone is sufficient to find its maximum amplitude and corresponding frequency. For example, the measured response during a chirp excitation passing through $f_{1}$ is shown in Fig. 6 .

This procedure, however, provides poor results when used during flow conditions because other hydrodynamic excitation sources including flow turbulence, vortex shedding and cavity collapse also induce significant vibrations in the structure. Consequently, the amplified resonant response is masked by noise. The averaged power spectra of signal responses measured under no flow, flow without cavitation and cavitation conditions are compared in Fig. 7 to demonstrate the different signal to noise ratios encountered with various flow types. These responses were generated with the same chirp excitation in terms of amplitude and frequency range in a bandwidth without any resonance from $180 \mathrm{~Hz}$ to $200 \mathrm{~Hz}$ at a rate of $2 \mathrm{~Hz} / \mathrm{s}$. Each $10-$ second time signal was divided into five segments, and the averaged power spectrum was computed. The broadband peak resulting from the sweeping excitation was clearly detected in the absence of flow. When the fluid flowed without cavitation, the vibration levels clearly increased in the entire baseband, but the dominant response corresponding to the mechanical excitation imposed by the patch was still observed. Finally, when cavitation occurred, an additional increase in noise was observed over the entire frequency range relative to the no cavitation conditions, indicating the presence of larger levels of induced vibrations. 


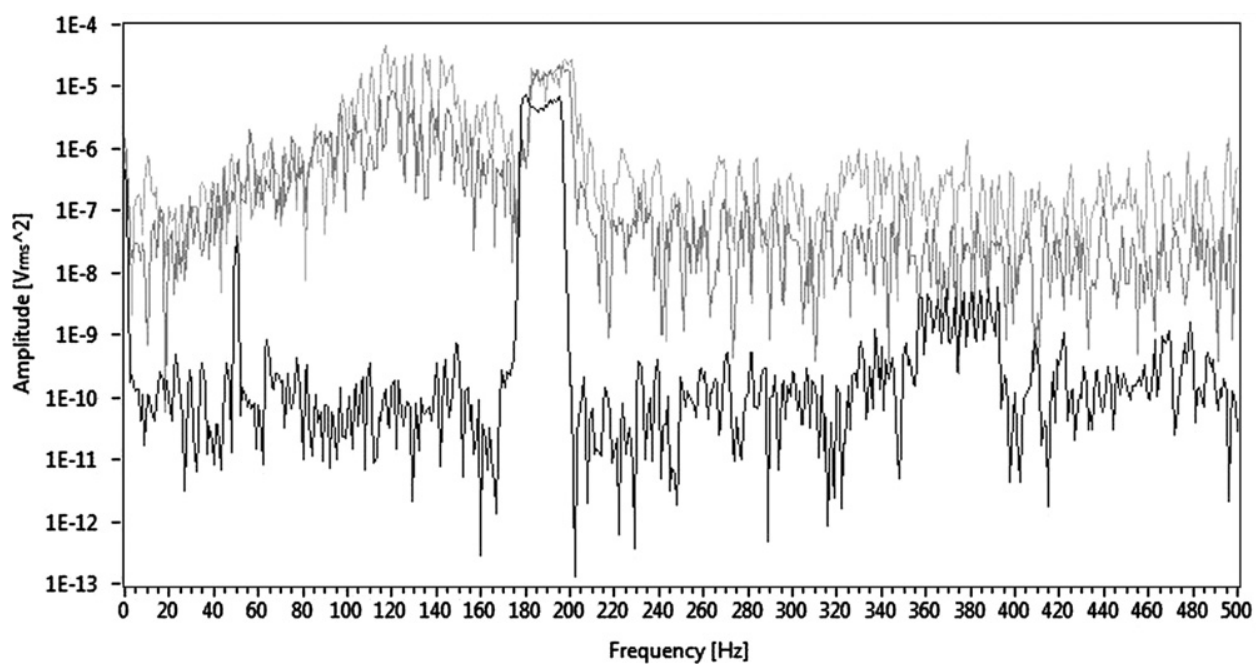

Fig. 7. Averaged power spectra measured under no flow (black), flow without cavitation (dark gray) and sheet cavitation (light gray) conditions for an incident angle of $2^{\circ}$ showing the response of the hydrofoil under a chirp excitation from $180 \mathrm{~Hz}$ to $200 \mathrm{~Hz}$.
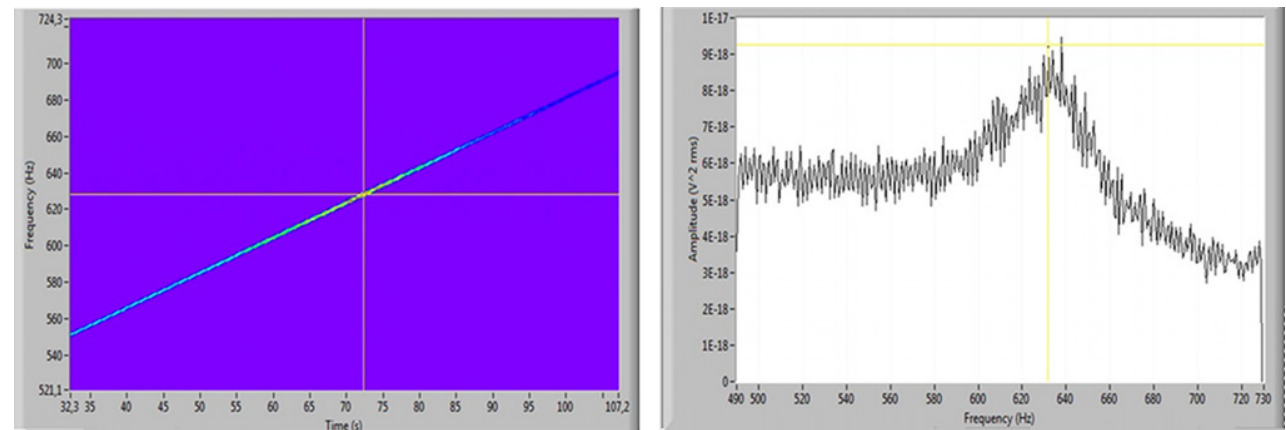

Fig. 8. Comparison of results obtained with the STFT (left) and the cross-correlation (right) post processing methods for the same signal.

To improve the detection of the natural frequencies from such noisy signals, two different signal processing techniques were used. In the first technique, the signal response from the patch was differentiated to enhance the responses at higher frequencies. Both the excitation and response signals were then filtered in sliding frequency bands of constant bandwidth ranging from the starting to the ending chirp frequency. Finally, these filtered signals were windowed and cross correlated to measure their level of similarity. From the amplitude analysis of the resulting cross-spectra at the chirp frequency, it was possible to visually identify the resonance conditions. To prevent misinterpretation of the graphs, a mathematical tool was used to approximate the real signal with a function. Several curve fitting options were tested. In particular, an equallyweighted third degree spline has shown good results minimizing the residuals, as calculated by Eq. (10):

$$
\text { Residue }=\frac{1}{L} \sum_{k=0}^{L-1} w_{k}\left[\left(x_{k}-x_{k}^{\prime}\right)^{2}+\left(y_{k}-y_{k}^{\prime}\right)^{2}\right],
$$

where $L$ is the length of the signal, $w_{k}$ is the $k$ th element of weight, $\left(x_{k}, y_{k}\right)$ is the signal $k$ th pair of elements and $\left(x_{k}{ }^{\prime}, y_{k}{ }^{\prime}\right)$ is the spline $k$ th pair of elements (see Fig. 11).

For verification purposes, a second signal processing method was also used, which consisted of a Joint Time Frequency Analysis (JTFA) based on the Short Time Fourier Transform (STFT) applied to low-pass filtered response signals to remove their high frequency noise. Using this technique, the Fast Fourier Transform (FFT) was consecutively applied to short segments of the time signal with an overlapping factor.

Both approaches showed good agreement. As an example for the case of a partial cavity with $l / c$ of approximately 0.02 at $2^{\circ}$, the frequency obtained with the STFT method was approximately $628.3 \mathrm{~Hz}$ (left side of Fig. 8) and approximately $632 \mathrm{~Hz}$ with the cross-correlation method (right side of Fig. 8). 


\subsection{Cavity surface ratio}

As a first approximation, the area of the hydrofoil surface covered by the sheet cavity was considered in order to study the added mass effect. Because the cavity is composed of a mixture of vapor/gas and water with a lower average density than pure water and also because it is in contact with the hydrofoil surface, the larger this area, the lower the added mass should be. Therefore, the Cavitation Surface Ratio (CSR) has been defined as the ratio between the area of the hydrofoil surface covered by the sheet cavity and the total hydrofoil surface including the suction and pressure sides (11). For simplicity, the cavity was considered to be of a constant length, $l$, along the span. The mean cavity length for each condition was calculated from the top side photographs such as the one shown in Fig. 9. In the case of supercavitation, the area occupied by cavities on the pressure side was also added to the calculation:

$$
\mathrm{CSR}=\frac{l \text { span }}{2 \operatorname{cspan}}=\frac{1}{2} \frac{l}{c}
$$

\subsection{Entrained mass relative to normal displacement}

The well-known fact that the added mass effect on a submerged structure depends on the particular mode shape that is excited, as proved by Yadikin et al. (2003), suggests that hydrofoil deformation plays an important role in the added mass effect. If cavitation occurs, it is not only the extent of surface covered by cavitation, accounted by the CSR, but also its location relative to the hydrofoil deformations that must be considered. Moreover, the mean density of the fluid inside the cavity in contact with the deforming structure is also relevant. Therefore, different density regions within the flow in contact with the hydrofoil surface must be distinguished. Consequently, the so-called entrained mass (EM) should be computed to better understand how the flow density and its location relative to the hydrofoil displacement influence the added mass effect. The $\mathrm{EM}_{i}$ is defined as the total fluid mass, $m_{i}$, displaced by the hydrofoil motion relative to the maximum normal surface displacement, $\Delta Y_{\text {max }_{i}}$, and is calculated as shown in Eq. (12) where $j$ is the number of flow regions and $i$ indicates the particular mode of vibration. This equation takes into account the mean density, $\bar{\rho}_{j}$, and the mean displacement of the contact surface, $\bar{d}_{j}$, of each type of region that can be obtained after discretization of the given area and the calculation of the local displacements at each node by Eq. (13), where $N$ is the total number of nodes:

$$
\begin{aligned}
& \mathrm{EM}_{i}=\frac{m_{i}}{\Delta Y_{\text {max }_{i}}}=\sum_{j} \bar{\rho}_{j}\left(\bar{d}_{j} \mathrm{AREA}_{j}\right), \\
& \bar{d}_{j}=\sum_{k}^{N} \frac{\left|\Delta Y_{k}\right|}{N \mid \Delta Y_{\text {max }_{i} \mid}} .
\end{aligned}
$$

From the cavitation lateral (Fig. 1) and top (Fig. 9) views, the area covered by the whole sheet cavity can be adequately identified and delimited. However, two different cavity morphologies can be distinguished depending on the visual aspect. For instance, on the top view in Fig. 9, the cavity appears to be quite transparent on both lateral sides while looking foamier in the central region. Increase transparency indicates a high void ratio that could be due to the 3-D effects of the
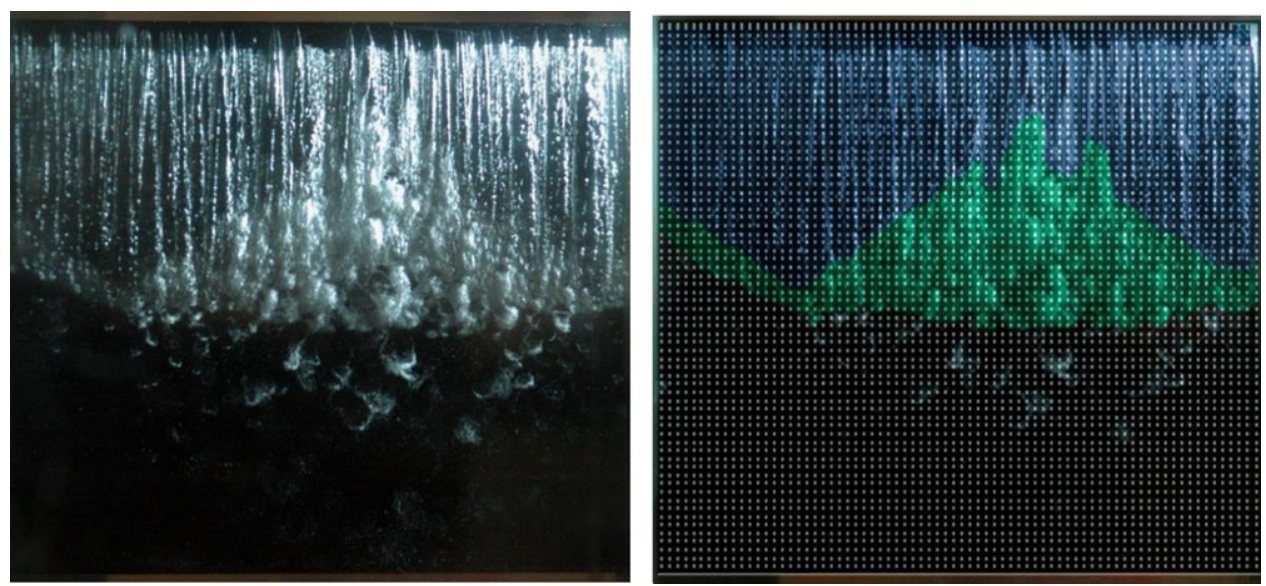

Fig. 9. (Left) Top view photograph of sheet cavitation on the hydrofoil suction side (flow from top to bottom). (Right) Example of zone identification with Ansys node discretization superimposed. (For interpretation of the references to color in this figure, the reader is referred to the web version of this article.) 


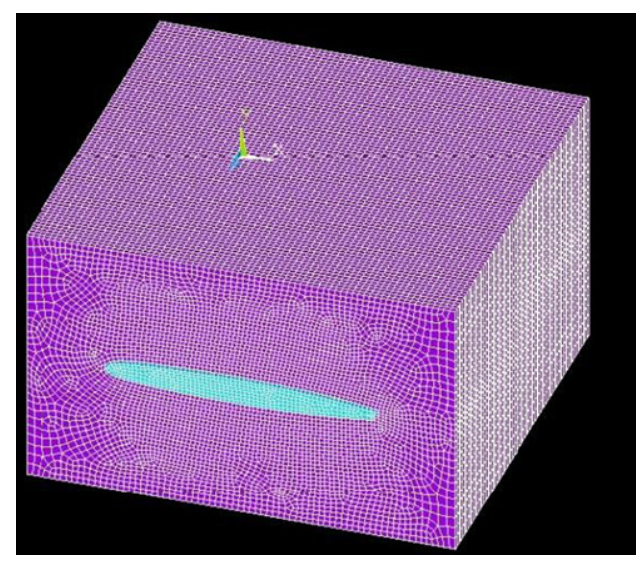

Fig. 10. Mesh of the solid and the fluid domains.

tunnel test section lateral walls. These effects suggest that the lateral sides of the cavity closure are not parallel to the spanwise direction, but oblique. Consequently, the reentrant jet direction is inclined towards the center of the leading edge and its component that is parallel to the flow is lower. Under such conditions, the cavity behavior is expected to exhibit a more stable behavior, and the amount of vapor phase is also increased (Franc and Michel, 2004). Therefore, these zones can be characterized with a higher void ratio. The central area where the cavity appears foamy is composed of the shedding of a mixture of small cavitating vortices/bubbles with water. This zone presents a more heterogeneous flow and a lower void ratio. The portion of the hydrofoil surface downstream of the closure region has been considered to be full of pure water, although some shed vortices can still be observed on it. In summary, three hydrofoil regions covered by different fluid flow densities were distinguished simply by visual observation of the photographs. One such example is shown on the right side of Fig. 9, where the transparent cavity is shown in blue, the foamy cavity in green and the no cavitating flow in black. This region identification is consistent with the work performed by Stutz and Reboud (1997) that suggests a cavitating flow pattern composed of different characteristic areas for sheet cavitation in a cavitation tunnel Venturi-type test section. They reported that the reverse flow due to the re-entrant jet decreases the void ratio along the cavity and that the maximum measured void ratios can reach approximately 0.8 .

For our calculations, cavitation was considered to be a biphasic mixture of water vapor and liquid with a pure water vapor density of $1.74 \times 10^{-2} \mathrm{~kg} / \mathrm{m}^{3}$ (saturated vapor at $20^{\circ} \mathrm{C}$ ) and a pure liquid water density of $1000 \mathrm{~kg} / \mathrm{m}^{3}$. A void ratio of 0.9 was given to the transparent cavitation regions and a value of 0.7 to the foamy regions. These values were selected to force the linear regressions shown in Fig. 14 to pass as close as possible to the origin as the entrained mass is expected to be negligible for the condition in air.

Because it was not possible to measure the hydrofoil displacements under resonance conditions during the experiments, a Finite Element Model (FEM) in the ANSYS ${ }^{\mathbb{R}}$ software was used to simulate the three mode shapes (Fig. 5). To ensure a consistent geometry, the NACA0009 profile was surrounded by a cubic volume of fluid (see Fig. 10) and several boundary conditions were defined. As the hydrofoil is clamped in the test section on one side, the equivalent area displacement was constrained in all three directions. All fluid walls were considered to be fully reflective. To ensure that there is no relative movement between the fluid and the hydrofoil, both domains were coupled by setting a fluid structure interaction condition in the interface. This particular condition at the fluid-structure mesh interface causes the acoustic pressure to exert a force on the structure, and the structural motion produces an effective fluid load. Then, the nodes at the interface have both pressure and displacement degrees of freedom. 28725 and 329250 hexahedral elements were used for the solid and fluid domains respectively. The solid domain was modeled as linearly elastic with isotropic material behavior. The fluid domain was simulated as a compressible and inviscid fluid with no net flow and whose mean density and pressure are uniform in the domain. Two modal analyses were performed that considered the fluid domain to be pure air and pure water. The numerical results in air and in still water were compared with those experimentally obtained using the methods explained in Section 4.3. As can be seen in Table 3, they show good agreement, with a maximum error of approximately $5 \%$, which was calculated as

$$
\text { error }(\%)=\frac{f_{\text {empirical }}-f_{\text {simulation }}}{f_{\text {simulation }}} 100 .
$$

From the FEM solution, the normal displacements of the element nodes on the top surface, $\left|\Delta Y_{k}\right|$, were obtained. Then, taking advantage of the domain discretization, the positions of all the element nodes was superimposed over the top photographs, as shown on the right of Fig. 9, such that each point corresponded to a node with a known absolute displacement. For simplicity, the geometry was assumed to be a flat plate. After dividing the total surface into three regions, each element node was assigned to its corresponding area with a given mean density. For each region, all displacements were averaged and normalized by the maximum normal displacement found for the total hydrofoil surface (13). Finally, Eq. (12) was developed to calculate the 
Table 3

Experimental and numerical natural frequencies of the hydrofoil in air and fully submerged in still water.

\begin{tabular}{clll}
\hline $\mathrm{Hz}$ & Empirical & Simulation & Error (\%) \\
\hline Air & & & \\
$f_{1}$ & 270.2 & 274.9 & 1.7 \\
$f_{2}$ & 1018.6 & 1024 & 0.5 \\
$f_{3}$ & 1671 & 1679.4 & 0.5 \\
Water & & & \\
$f_{1}$ & 130.2 & 125.3 & 3.9 \\
$f_{2}$ & 614.8 & 630 & 2.4 \\
$f_{3}$ & 886 & 932.8 & 5 \\
\hline
\end{tabular}
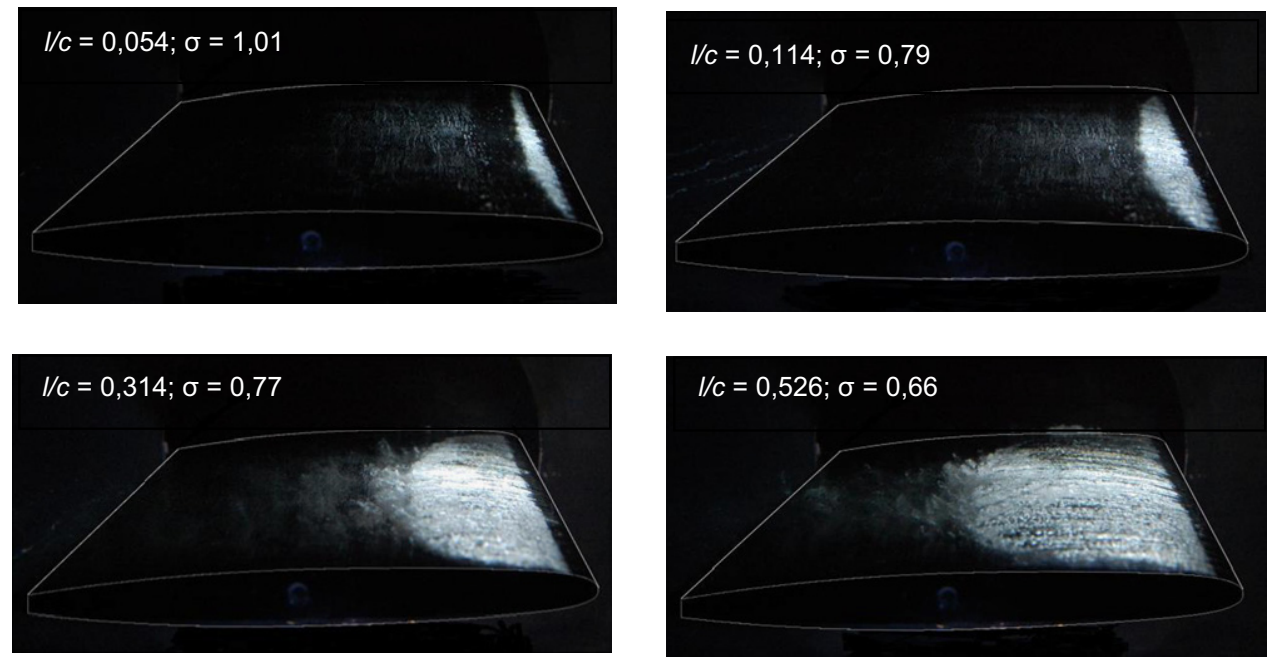

Fig. 11. Photographs of the cavitating flow at different sigma values (from right to left) at $14 \mathrm{~m} / \mathrm{s}$ for $1^{\circ}$ (top) and $2^{\circ}$ (bottom) incidence angles.

approximate entrained mass $\mathrm{EM}_{i}$ by considering the so-called "trans" (for transparent), "foamy" and "water" regions. The first two correspond to the cavity and the last corresponds to the flow outside the cavity.

$$
\mathrm{EM}_{i}=\left[\bar{\rho}_{i} \bar{d}_{i} \mathrm{AREA}\right]_{\text {trans }}+\left[\bar{\rho}_{i} \bar{d}_{i} \mathrm{AREA}\right]_{\text {foamy }}+\left[\bar{\rho}_{i} \bar{d}_{i} \mathrm{AREA}\right]_{\text {water }}
$$

\section{Results and discussions}

The photographs in Fig. 11 show some examples of the stable sheet cavities observed during the tests at $1^{\circ}$ (top) and $2^{\circ}$ (bottom). In the top photographs, a short cavity occurs that extends the roughness band downstream. As sigma is decreased, the cavity length clearly increases. It should also be noted that a small number of cavitation spots have also appeared on the pressure side of the hydrofoil at both incidence angles, but only during supercavitation conditions.

The plots in Fig. 12 show the evolution of the amplitude of the gain between the response and the excitation signals at the wave sine frequency around $f_{3}$ for an incident angle of $1^{\circ}$. Rather than use visual identification, a third degree spline curve fitting was calculated to establish a criterion to select the maximum amplitude and the corresponding frequency. The resulting curves, shown in red, were obtained by considering approximately 200 equally distributed samples focused on the approximate peak. Analogous treatments were performed for all other testing conditions.

In Table 4 , the values of $f_{1}, f_{2}$ and $f_{3}$ are listed for the tests performed at $1^{\circ}$ and $2^{\circ}$ with the test section empty of water (air), full up to its lower side (half wetted), completely full with still water (water), and with a flow velocity of $7 \mathrm{~m} / \mathrm{s}$ and $14 \mathrm{~m} / \mathrm{s}$ without cavitation. The frequencies corresponding to the hydrofoil in air were taken as $f_{\text {vacuum }}$ to quantify the added mass coefficient, $C_{M}$, defined by Eq. (7).

In Tables 5 and 6 , the results for $f_{2}$ and $f_{3}$ at $14 \mathrm{~m} / \mathrm{s}$ with different cavitation conditions are presented for $1^{\circ}$ and $2^{\circ}$, respectively. The cavity length to chord ratio, the sigma, the CSR, the EM and the $C_{M}$ are indicated. The last row of data corresponds to supercavitation. In particular, the percent uncertainty was estimated to be approximately $9 \%$ for $l / c$ and CSR, 3\% for $\sigma, 2 \%$ for $C_{M}$ and between $4 \%$ (long cavities) and $10 \%$ (short cavities) for EM. For the frequencies calculation, it is approximately $1 \%$. 

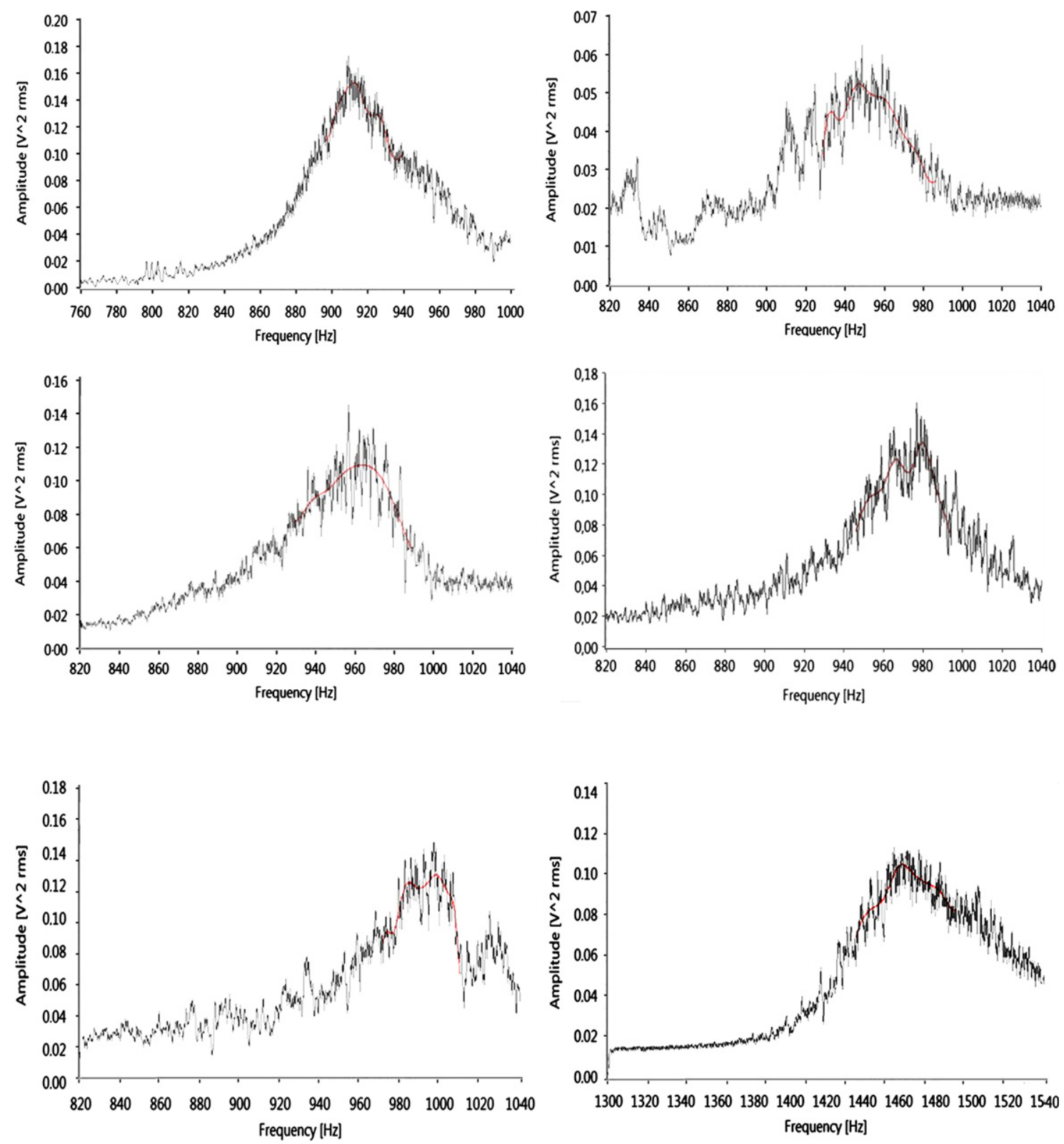

Fig. 12. Response gains as a function of excitation frequency (gray) and spline approximations (red) used to identify $f_{3}$ at $1^{\circ}$ for each sheet cavitation scenario. (For interpretation of the references to color in this figure legend, the reader is referred to the web version of this article.)

Table 4

Natural frequencies and $C_{M}$ values of the hydrofoil in air, partially (half wetted) and completely submerged in still water, and with no cavitation flows at 7 and $14 \mathrm{~m} / \mathrm{s}$ for incident angles of $1^{\circ}$ and $2^{\circ}$ (in the latter cases the sigma is also indicated).

\begin{tabular}{|c|c|c|c|c|c|c|c|}
\hline & \multirow[t]{2}{*}{$\sigma$} & \multicolumn{2}{|c|}{ 1st bending } & \multicolumn{2}{|c|}{ 1st torsion } & \multicolumn{2}{|c|}{ 2nd bending } \\
\hline & & $f_{1}[\mathrm{~Hz}]$ & $C_{M 1}$ & $f_{2}[\mathrm{~Hz}]$ & $C_{M 2}$ & $f_{3}[\mathrm{~Hz}]$ & $C_{M 3}$ \\
\hline Air & & 270.2 & 0.00 & 1018.6 & 0.00 & 1671.0 & 0.00 \\
\hline Half Wetted & & 163.0 & 1.75 & 755.0 & 0.82 & 1113.6 & 1.25 \\
\hline Water & & 130.2 & 3.31 & 614.8 & 1.74 & 886.0 & 2.56 \\
\hline $7 \mathrm{~m} / \mathrm{s}, 1^{\circ}$ & 3.05 & 130.6 & 3.28 & 621.1 & 1.69 & 895.8 & 2.48 \\
\hline $7 \mathrm{~m} / \mathrm{s}, 2^{\circ}$ & 3.03 & 130.0 & 3.32 & 621.1 & 1.69 & 883.2 & 2.58 \\
\hline $14 \mathrm{~m} / \mathrm{s}, 1^{\circ}$ & 2.48 & 134.4 & 3.04 & 629.3 & 1.62 & 913.0 & 2.35 \\
\hline $14 \mathrm{~m} / \mathrm{s}, 2^{\circ}$ & 2.48 & 132.0 & 3.19 & 634.2 & 1.58 & 911.6 & 2.36 \\
\hline
\end{tabular}


Table 5

Cavity length to chord ratio, sigma, CSR, EM and $C_{M}$ for $f_{2}$ and $f_{3}$ at $1^{\circ}$.

\begin{tabular}{|c|c|c|c|c|c|c|}
\hline$l / c$ & $\sigma$ & CSR & $\mathrm{EM}_{2}$ & $\mathrm{EM}_{3}$ & $C_{M 2}$ & $C_{M 3}$ \\
\hline 0.02 & 1.539 & 0.01 & 4.20 & 5.24 & 1.6 & 2.35 \\
\hline 0.054 & 1.006 & 0.027 & 4.05 & 5.10 & 1.82 & 2.08 \\
\hline 0.114 & 0.79 & 0.057 & 3.83 & 4.92 & 1.73 & 1.99 \\
\hline 0.318 & 0.6 & 0.159 & 3.11 & 4.11 & 1.61 & 1.92 \\
\hline 0.442 & 0.543 & 0.221 & 2.90 & 3.53 & 1.26 & 1.81 \\
\hline$>1$ & 0.264 & 0.598 & 0.44 & 0.54 & 0.23 & 0.31 \\
\hline
\end{tabular}

Table 6

Cavity length to chord ratio, sigma, CSR, EM and $C_{M}$ for $f_{2}$ and $f_{3}$ at 2 .

\begin{tabular}{|c|c|c|c|c|c|c|}
\hline$l / c$ & $\sigma$ & CSR & $\mathrm{EM}_{2}$ & $\mathrm{EM}_{3}$ & $C_{M 2}$ & $C_{M 3}$ \\
\hline 0.02 & 1.74 & 0.01 & 4.19 & 5.23 & 1.58 & 2.37 \\
\hline 0.054 & 1.327 & 0.027 & 4.07 & 5.13 & 1.72 & 2.07 \\
\hline 0.156 & 0.93 & 0.078 & 3.65 & 4.76 & 1.72 & 2.06 \\
\hline 0.314 & 0.77 & 0.157 & 3.24 & 4.30 & 1.35 & 2.03 \\
\hline 0.526 & 0.66 & 0.263 & 2.87 & 3.53 & 1.14 & 1.85 \\
\hline 0.754 & 0.62 & 0.377 & 2.43 & 2.57 & 1 & 1.53 \\
\hline$>1$ & 0.272 & 0.597 & 0.44 & 0.54 & 0.34 & 0.42 \\
\hline
\end{tabular}

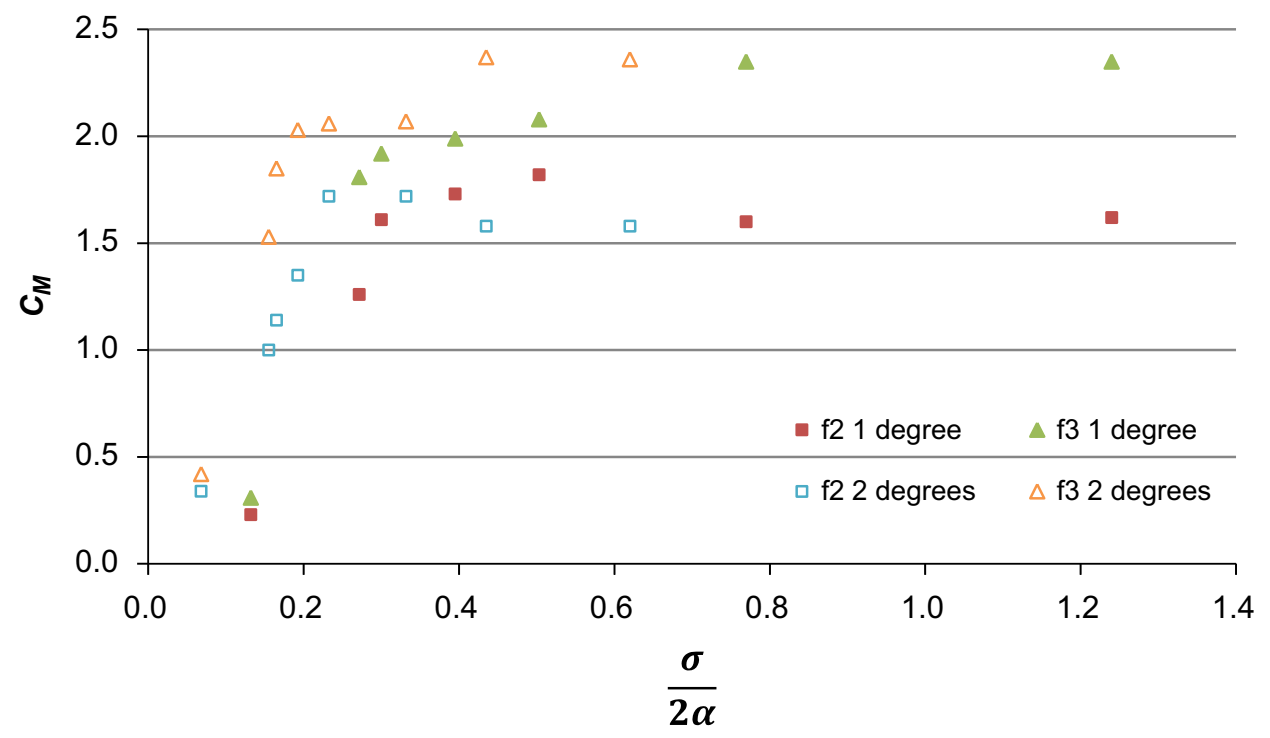

Fig. 13. Added mass coefficients as a function of sigma/(2 $\alpha)$ for $f_{2}$ and $f_{3}$ at $1^{\circ}$ and $2^{\circ}$.

An examination of the figures suggests that for each mode, the maximum added mass coefficient corresponds to the situation in which the hydrofoil is completely submerged in still water. Comparing the results of various modes, the largest effects are found for the 1 st bending $\left(C_{M 1} \approx 3.31\right)$, followed by the 2 nd bending $\left(C_{M 3} \approx 2.56\right)$ with lower effects occurring in the torsion mode $\left(C_{M 2} \approx 1.74\right)$. The fact that the added mass depends on the mode shape has been observed in previous studies, i.e. the experimental one of Rodriguez et al. (2006). Furthermore, Yadykin et al. (2003) predicted that higher harmonics should exhibit less significant effects, as it occurs between the two bending modes in our case.

If the hydrofoil is half wetted with still water, the coefficients are reduced by approximately $50 \%$ for all modes.

For flowing conditions without cavitation, the added mass coefficients are similar for both incident angles, with no apparent correlation with the angular position. However, the effects of supercavitation are slightly larger at $2^{\circ}$ than at $1^{\circ}$ with an approximate increase of $47 \%$ for $f_{2}$ and of $35 \%$ for $f_{3}$.

Another interesting comparison can be made between the results obtained with the half wetted profile and with supercavitation. The supercavitation added mass difference may result from the free surface effect. When performing the modal analysis of the half wetted hydrofoil, traveling pressure waves caused by the structure motion are clearly seen on the free surface. These waves would lead the fluid-structure system to a higher modal mass. 


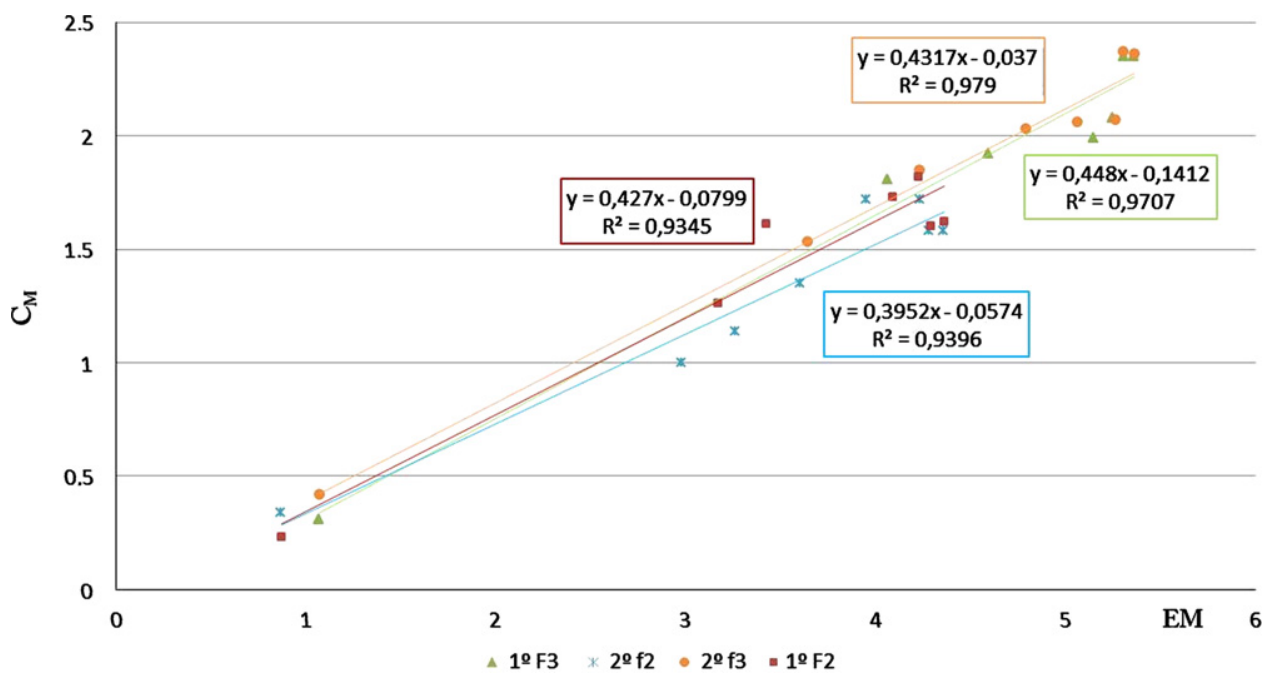

Fig. 14. Added mass coefficients as a function of entrained mass for $f_{2}$ and $f_{3}$ at $1^{\circ}$ and $2^{\circ}$.

To analyze the added mass effects under sheet cavitation conditions, the $C_{M}$, s indicated in Tables 5 and 6 for $f_{2}$ and $f_{3}$ are plotted in Figs. 13 and 14 as functions of $\sigma / 2 \alpha$ and EM respectively. In Fig. 13, the trends show that the added mass effects decrease with decreasing $\sigma / 2 \alpha$. This decrease in $\sigma / 2 \alpha$ increases the dimensions of the attached cavity as quantified by the CSR. Nevertheless, the data appear dispersed in Fig. 13 with no linear dependence on $\sigma / 2 \alpha$. This result supports the notion that the average density of the cavity and its location relative to the hydrofoil deformations plays a role in these effects. This hypothesis is confirmed by the correlation between the $C_{M}$ s and the EM's presented in Fig. 14 . In this case, the data points from different cases exhibit a similar linear dependence. A linear regression was calculated for the two modes and the two incident angles. The resulting equations and coefficients of determination, $R^{2}$, are indicated on the graph. For each of the regressions, the $R^{2}$ is above 0.9 , which validates the approach based on the EM concept and permits its use as an appropriate technique to predict the added mass effects in cavitating hydrofoils.

\section{Conclusions}

The added mass effects of the flow surrounding a 2-D NACA009 hydrofoil have been experimentally determined with still water, flowing water without cavitation, sheet cavities of different sizes and with supercavitation. For that purpose, two PZT patches mounted on the hydrofoil surface were successfully used to excite and measure the frequency response without altering the flow. The variation of the hydrofoil natural frequencies relative to the air condition has permitted the calculation of the added mass coefficients.

The maximum added mass coefficients were found for the hydrofoil completely submerged in still water. In this case, the largest effects corresponded to the 1 st bending mode $f_{1}\left(C_{M} \approx 3.31\right)$, followed by the 2 nd bending mode $f_{3}\left(C_{M} \approx 2.56\right)$. The lower effects occurred in the torsion mode $f_{2}\left(C_{M} \approx 1.74\right)$.

If the hydrofoil is half-wetted with still water, the effects are approximately reduced by $50 \%$ relative to the fully wetted condition. However, the results with supercavitation are between $70 \%$ and $83 \%$ lower than in the half wetted condition.

With an incident angle of $2^{\circ}$, the effects of supercavitation were slightly larger than at $1^{\circ}$. Meanwhile similar effects for both incident angles were found for flowing conditions without cavitation.

For sheet cavitation conditions, the added mass effects for modes $f_{2}$ and $f_{3}$ decrease with $\sigma$ because of increases in the CSR. The added mass coefficients exhibit similar linear correlation with the EM. The EM takes into account the dimensions and average density of the macro-cavity as well as the relative displacements of the surrounding two-phase flows induced by the specific hydrofoil deformations at each resonance. This result confirms the validity of the experimental data obtained using the set-up and methodology described previously. The parameters influencing the added mass effects on hydrofoils under sheet cavitation conditions were also identified.

\section{Acknowledgments}

The present investigation is part of the work performed for the Hydrodyna Phase II research project. The authors would like to acknowledge all the partners of the project (ANDRITZ Hydro, ALSTOM Hydro, VOITH Hydro, LMH-EPFL, and CDIF-UPC) for their collaboration. 


\section{References}

Aeschlimann, V., Barre, S., Legoupil, S., 2011. X-ray attenuation measurements in a cavitating mixing layer for instantaneous two-dimensional void ratio determination. Physics of Fluids, 23.

Amabili, M., 1996. Free vibration of partially filled, horizontal cylindrical shell. Journal of Sound and Vibration 191, 757-780.

Amromin, E., Hansberger, J., Wang, H., Wosnik, M., Arndt, R.E.A., 2003. Investigation of a low-drag, partially cavitating hydrofoil. In: Proceedings of the Fifth International Symposium on Cavitation, Osaka.

Amromin, E., Kovinskaya, S., 2000. Vibration of cavitating elastic wing in a periodically perturbed flow: excitation of subharmonics. Journal of Fluids and Structures 14, 735-751.

Ausoni, Ph., Farhat, M., Escaler, X., Egusquiza, E., Avellan, F, 2007. Cavitation influence on von Kármán vortex shedding and induced hydrofoil vibrations. Journal of Fluids Engineering 129 (8), 966. (8 pages).

Avellan, F., Henry, P., Ryhming, I.L., 1987. A new high speed cavitation tunnel. ASME Winter Annual Meeting, Boston, vol. 57, pp. 49-60.

Benaouicha, M., Astolfi, J.A., 2012. Analysis of added mass in cavitating flow. Journal of Fluids and Structures 31, 30-48.

Blevins, R.D., 1979. Formulas for Natural Frequency and Mode Shape. Krieger, Malabar.

Brennen, C., 1982. A review of added mass and fluid inertial forces. Naval Civil Engineering Laboratory.

Conca, C., Osses, A., Planchard, J., 1997. Added mass and damping in fluid-structure interaction. Computer Methods in Applied Mechanics and Engineering 146, 387-405.

Coutier-Delgosha, O., Devillers, J.F., Pichon, T., Vabre, A., Woo, R., Legoupil, S., 2006. Internal structure and dynamics of sheet cavitation. Physics of Fluids $18,017103$.

Ducoin, A., Astolfi, J.A., Gobert, M.L., 2010a. An Experimental Study of Boundary-layer Transition Induced Vibrations on a Hydrofoil, FEDSM-ICNM2010, Montreal.

Ducoin, A., Young, Y.L., Sigrist, J.F., 2010b. Hydroelastic Responses of a Flexible Hydrofoil in Turbulent, Cavitating Flow. FEDSM-ICNM2010, Montreal.

Escaler, X., Farhat, M., Egusquiza, E., Avellan, F., 2007. Dynamics and intensity of erosive partial cavitation. Fluids Engineering Division of ASME 129, $886-893$.

Fine, N.E, Uhlman, J.S., Kring, D.C., 2001. Calculation of the added mass and damping forces on supercavitating bodies. In: Proceedings of the Fourth International Symposium on Cavitation (CAV 2001), June 20-23, 2001, California Institute of Technology, Pasadena, CA, USA.

Franc, J.P, Michel, J.M., 2004. Fundamentals of Cavitation. Kluwer Academic Publishers, Dordrecht.

Ishii, M., 1975. Thermo-Fluid Dynamic Theory of Two-Phase Flow. Eyrolles, Paris.

Kimber, M., Lonergan, R., Garimella, S.V., 2009. Experimental study of aerodynamic damping in arrays of vibrating cantilevers. Journal of Fluids and Structures 25, 1334-1347.

Knapp, R.T., Daily, J.W., Hammit, F.G., 1970. Cavitation. McGraw-Hill, New York

Liang, Q.W, Rodriguez, C.G, Egusquiza, E., Escaler, X., Farhat, M., Avellan, F., 2007. Numerical simulation of fluid added mass effect on a Francis turbine runner. Computer and Fluids 36, 1106-1118.

Lindholm, U.S., Kana, D.D., Chu, W.-C., Abramson, H.N., 1965. Elastic vibration characteristics of cantilever plates in water. Journal of Ship Research 9, $11-22$.

Moussou, P., 2005. A kinematic method for the computation of the natural modes of Fluid-Structure Interaction Systems. Journal of Fluids and Structures 20, 643-658.

Münch, C., Ausoni, P., Braun, O., Farhat, M., Avellan, F., 2010. Fluid-structure coupling for an oscillating hydrofoil. Journal of Fluids and Structures 26, 1018-1033.

Olofsson, N., 1996. Force and Flow Characteristics of a Partially Submerged Propeller, Ph.D. Thesis, Department of Naval Architecture and Ocean Engineering, Chalmers University of Technology, Gothenburg, Sweden.

Rodriguez, C.G., Egusquiza, E., Escaler, X., Liang, Q.W., Avellan, F., 2006. Experimental investigation of added mass effects on a Francis turbine runner in still water. Journal of Fluids and Structures 22, 699-712.

Sewall, J.L., Miserentino, R., Pappa, R.S., 1983. Vibration studies of a lightweight three-sided membrane suitable for space application. NASA Technical, 2095.

Stutz, B., Legoupil, S., 2003. X-ray measurements within unsteady cavitation. Experiments in Fluids 35, $130-138$.

Stutz, B., Reboud, J.-L., 1997. Two-phase flow structure of sheet cavitation. Physics of Fluids 9 (12).

Yadykin, Y., Tenetov, V., Levin, D., 2003. The added mass of a flexible plate oscillating in a fluid. Journal of Fluids and Structures $17,115-123$.

Young, Y.L., 2007. Time-dependent hydroelastic analysis of cavitating propulsors. Journal of Fluids and Structures 23, $269-295$.

Young, Y.L., Savander, B.R., 2011. Numerical Analysis of Large-Scale Surface-Piercing Propellers. Ocean Engineering 38, $1368-1381$. 